\title{
Performance Evaluation of Tergitol NP-7 and Triton X-114 for the Removal of Crystal Violet Using Cloud-point Extraction
}

\author{
D. Duraimurugan, ${ }^{a}$ L. Mathuri, ${ }^{a}$ J. Indulekha, ${ }^{a}$ R. Anantharaj, ${ }^{b}$ and A. Arunagiri ${ }^{a,{ }^{*}}$ \\ ${ }^{a}$ Department of Chemical Engineering, National Institute of Technology, \\ doi: 10.15255/CABEQ.2014.2143 \\ Tiruchirappalli 620015, Tamil Nadu, India \\ ${ }^{b}$ Department of Chemical Engineering, SSN College of Engineering, \\ Kalavakkam - 603110, Tamil Nadu, India \\ Original scientific paper \\ Received: October 31, 2014 \\ Accepted: June 3, 2016
}

In the present study, a cloud-point extraction process has been developed to remove crystal violet dye using two different non-ionic surfactants, Tergitol NP-7 and Triton $\mathrm{X}-114$. For different concentrations of dye and surfactant, cloud-point temperatures were determined for Tergitol NP-7 and Triton X-114. The effectiveness of two different surfactants, Triton X-114 and Tergitol NP-7, for the removal of dye from synthetic solution was investigated. The effects of surfactant and dye concentrations, as well as operating temperature on phase volume ratio, preconcentration factor, distribution coefficient, and extraction efficiency were studied. The optimum dosage of surfactant can be $0.05 \mathrm{M}$ for both surfactants for removing crystal violet. The results showed that $97 \%$ of crystal violet can quantitatively be removed by cloud-point extraction at $0.05 \mathrm{M}$ surfactant concentration in a single extraction. The performance of Tergitol NP-7 was found to be more effective than Triton X-114 for the removal of crystal violet using CPE.

Key words:

cloud-point extraction, crystal violet, Tergitol NP-7, Triton X-114, extraction efficiency

\section{Introduction}

Removal of dyes from wastewater is one of the most significant problems faced by the dyestuff manufacturing, textile dyeing, and printing industries $^{1}$. Disposal of this untreated wastewater into water bodies can cause serious health problems like allergies and skin cancer. It will also give rise to some environmental problems, as they will interfere with photosynthetic activity and hence affect aquatic life ${ }^{2}$. Crystal violet $(\mathrm{CV})$, being a basic cationic dye, is the brightest class of dye and has a very high tinctorial value ${ }^{3}$. It is very difficult to remove because of its non-biodegradable synthetic nature and high solubility in water ${ }^{4}$. It is basically used in the histological stain and in Gram's Method of classifying bacteria, for ball-point pens, as a dermatological agent, a veterinary medicine, an additive to poultry feed to inhibit propagation of mold, intestinal parasites and fungus, etc., in inkjet printers, fingerprinting, for dyeing paper, and DNA gel electrophoresis $^{5}$. Many methods are in practice for color removal, like membrane separation, coagulation, flocculation, ozonation, oxidation, adsorption, photocatalysis ${ }^{6-8}$. However, every method has some

"Corresponding author: Tel: +91-431-2503114;

Fax:+91-431-2500133; email: aagiri@nitt.edu limitation, and they are also economically infeasible. For example, in the case of adsorption, activated carbon is expensive, while in membrane separation there are chances of fouling which decreases the flux ${ }^{9}$.

Cloud-point extraction (CPE) is an effective separation technique for the removal of dissolved organic contaminants from effluents ${ }^{10-21}$. Aqueous solutions of non-ionic surfactants turn cloudy at a definite temperature, and this temperature is referred to as the cloud-point (CPT). By allowing the solution to settle at a temperature above the cloudpoint, phase separation takes place. The smaller phase contains most of the surfactant and usually sinks to the bottom, in some cases at the top, called the surfactant-rich phase or coacervate phase, while the more voluminous aqueous supernatant, also called the dilute phase, has a surfactant content approximately equal to the critical micellar concentration $(\mathrm{CMC})^{22}$. This is known as cloud-point extraction $(\mathrm{CPE})$. The dilute phase, which contains a very low concentration of pollutant, can be discharged into the environment. Cloud-point extraction using non-ionic surfactant is an alternative method for the removal of dyes from wastewater ${ }^{6,23}$.

The actual reason of phase separation is not known. However, some researchers have proposed different explanations for phase separation in CPE. 
Micellar interactions, which are repulsive at lower temperature, become attractive at higher temperature $^{24}$. Dehydration occurs in the external layer of the micelles at higher temperature. The dielectric constant of water decreases at elevated temperature and water becomes a poor solvent for the hydrophilic part of the surfactant molecules, leading to phase separation ${ }^{25}$. At higher temperature, the micellar aggregation number and micellar size increases causing phase separation ${ }^{26}$. The main advantage of CPE is that it uses a much less amount of surfactant, which is non-volatile and disposable in nature, while the other advantage is that it often uses water as solvent ${ }^{27}$. Although the CPE technique bears many advantages over the traditional liquid-liquid extraction process, that it is reversible, flexible, biodegradable, easy to handle, more efficient, safe and non-toxic, very few works related to the separation of pollutants have been performed ${ }^{28}$. The cloudpoint system can also be used for separation and purification of metal ions, organic compounds, and bioactive materials ${ }^{29}$. It is also used to preconcentrate copper, nickel, zinc and iron ions in environmental samples and remove oil from soil as well as heavy metals and toxic solutes like phenol from polluted water ${ }^{30}$. In order to make the cloud-point extraction process more economical, the organic compounds must be stripped from the non-ionic surfactant to enable its reutilization ${ }^{1}$.

Non-ionic surfactants are compatible with other types, and are excellent candidates to enter complex mixtures, as found in many commercial products. They are much less sensitive to electrolytes, particularly divalent cations, than ionic surfactants, and can be used with highly saline or hard water. They exhibit a very low toxicity level, and are used in pharmaceuticals, cosmetics, and food products. Non-ionic surfactants are found today in a large variety of domestic and industrial products, such as powdered or liquid formulations ${ }^{31}$.

In the present study, an attempt was made to compare the performance of two different non-ionic surfactants, Tergitol NP-7 and Triton X-114, to remove crystal violet from a synthetic dye solution by the cloud-point extraction process. Among various dyes, crystal violet (CV) is a well-known dye used for various purposes, as listed earlier, which is why it was selected for the present study. The cloudpoint of Tergitol NP-7 and Triton X-114 is relatively low and the experiments could be conducted at room temperature, which makes them the suitable choice of non-ionic surfactants for the present study. The effects of temperature, surfactant concentration, and dye concentration on various parameters like phase volume ratio, preconcentration factor, distribution coefficient, and extraction efficiency were studied.

\section{Experimental}

\section{Materials}

Triton X-114 (Octyl phenol poly ethylene glycol ether, density at $298 \mathrm{~K}$ is $1.058 \mathrm{~g} \mathrm{~mL}^{-1}$, mol. wt.: $\left.537 \mathrm{~g} \mathrm{~mol}^{-1}, \lambda_{\max }: 223 \mathrm{~nm}\right)$ and Tergitol NP-7 (Nonyl phenol ethoxylate, density at $298 \mathrm{~K}$ is 1.044 g mL ${ }^{-1}$, mol. wt.: $528 \mathrm{~g} \mathrm{~mol}^{-1}, \lambda_{\max }: 235 \mathrm{~nm}$ ), purchased from Sigma Life Sciences India, have been used as non-ionic surfactants. The critical micellar concentrations (CMC) of TX-114 and Tergitol NP-7 at $298 \mathrm{~K}$ are $2.1 \cdot 10^{-4} \mathrm{M}$ and $7.3 \cdot 10^{-5} \mathrm{M}$, respectively. Crystal violet (mol. wt.: $497.979 \mathrm{~g} \mathrm{~g}^{-1} \mathrm{~mol}^{-1}$, density: $1.198 \mathrm{~g} \mathrm{~mL}^{-1}, \lambda_{\max }: 590 \mathrm{~nm}$ ) of analytical grade was purchased from Sigma Life Sciences, India. The surfactants and dye were used without further purification. JASCO UV spectrophotometer was used for calibration and measuring dye concentration in dilute phase after phase separation. Water bath, purchased from TECHNICO Laboratory Products, Chennai, was used for maintaining temperature for cloud-point extraction. The chemical structure of surfactants and crystal violet dye is given in Figure 1, Figure 2 and Figure 3.

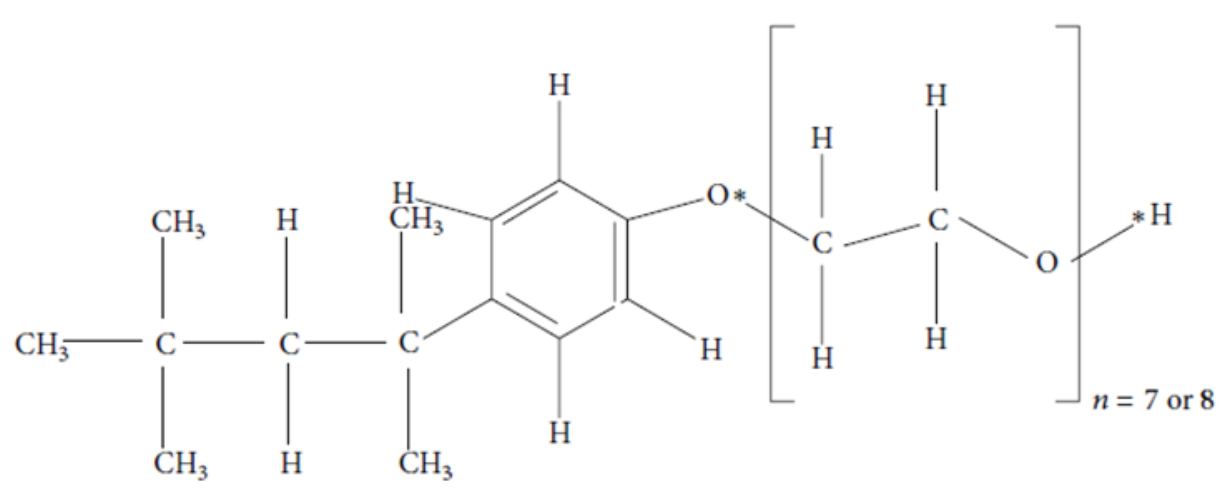

Fig. 1 - Chemical structure of Triton X-114 
<smiles>OCCOc1ccc(-c2ccccc2)cc1</smiles>

Fig. 2 - Chemical structure of Tergitol NP-7<smiles>CN(C)c1ccc(C(=C2C=CC(=[N+](C)C)C=C2)c2ccc(N(C)C)cc2)cc1</smiles>

Fig. 3 -Chemical structure of Crystal violet

\section{Methods}

\section{Determination of cloud-point temperature}

The cloud-point of the aqueous surfactant solution was determined by heating $10 \mathrm{~mL}$ of such micellar solution in glass tubes. For heating the solution, a thermostatic bath was used. The rate of temperature increase in the water bath was set at 1 $\mathrm{K}$ per min. The cloud-point was determined by visual observation at the temperature at which the solution became obviously turbid. The solution was heated above cloud-point and then separated into two phases. On cooling, the solution became transparent. The experiments were repeated for different combinations of surfactant and solute concentrations. All the cloud-points reported in this work are the average of at least triplicate measurements, and the variation of error is no more than $1 \mathrm{~K}$.

\section{Cloud-point extraction (CPE)}

An amount of $50 \mathrm{~mL}$ of micellar solution containing crystal violet dye and Tergitol NP-7 and Triton X-114 were taken. For different concentrations of crystal violet, such as 25,50 , and $75 \mathrm{mg} \mathrm{L}^{-1}$, the concentration of surfactant varied from $0.01 \mathrm{M}$ to $0.1 \mathrm{M}$. Each set of samples was kept in the thermostatic bath maintained at operating temperatures for 30 minutes. The heated solution was allowed to settle for 1 hour. The volumes of surfactant-rich phase and dilute phase were noted. Calibration of UV spectrophotometer for crystal violet was carried out by preparing dye solutions of known concentrations. The concentration of crystal violet in dilute phase was then determined by UV spectrophotometer. The surfactant-rich phase concentration was obtained from material balance calculations. The phase volume ratio, preconcentration factor, distribution coefficient, and extraction efficiency were then determined for all solute and surfactant concentrations, as well as operating temperatures.

\section{Results and discussions}

\section{Cloud-point temperature}

The cloud-point of a non-ionic surfactant can be influenced by many factors, such as its own concentration, and the number of ethylene oxide units in its molecules, as well as the additives, like electrolytes $^{32}$. To ensure the cloud-point extraction process at the desired temperature, it is important to have detailed information on the clouding behaviors and cloud-point temperatures of surfactants. The effect of surfactant and solute concentration on the cloud-points were analyzed in the present study.

Figure 4 and Figure 5 show the effect of surfactant and solute concentrations on the cloud-

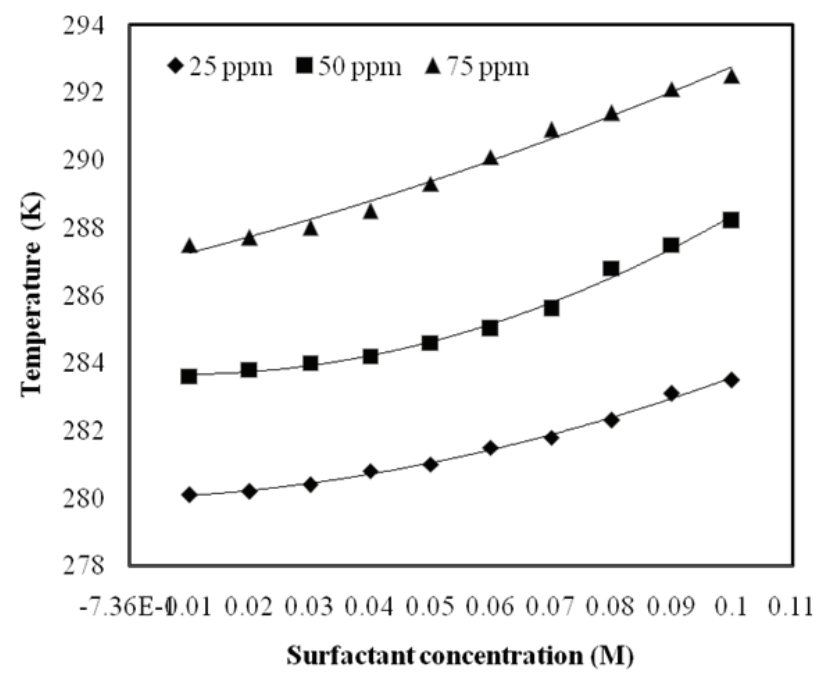

Fig. 4 - Effect of Tergitol NP-7 and dye concentration on cloud-point

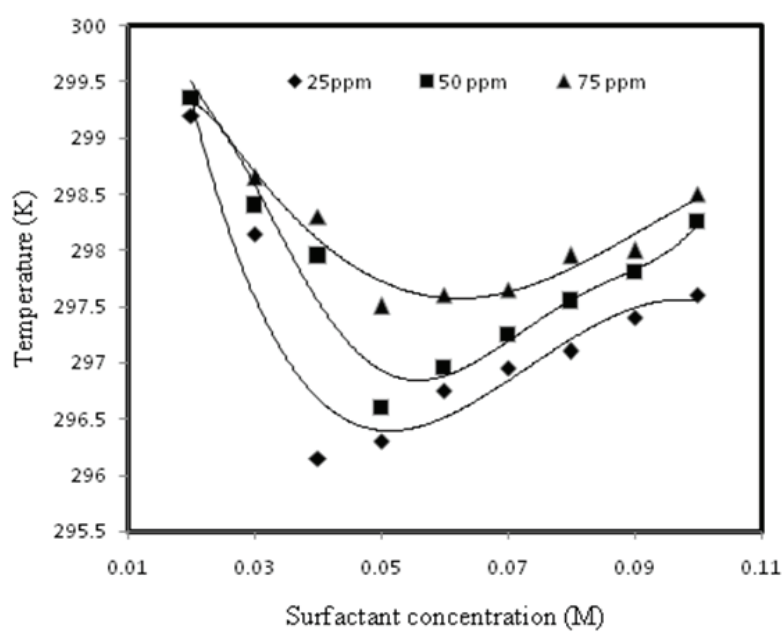

Fig. 5 - Effect of Triton X-114 and dye concentration on cloud-point 
points of Tergitol NP-7 and Triton X-114, respectively. Initially, the CPT of Triton X-114 decreases sharply with increasing surfactant concentration, and then gradually increases with further increase in surfactant concentration, both of which represent typical clouding behaviors of non-ionic polyethoxylated surfactants ${ }^{33}$. The decrease in CPT with increase in surfactant concentration of Triton X-114 is due to increase in micellar concentration, while the phase separation results from increased micellar interaction. CPT of Tergitol NP-7 increases gradually with increasing surfactant concentration. The increase in CPT is due to the structured water-surfactant system present in the micelles, which breaks at high surfactant concentrations. Even then, the molecules do not become free of the surfactant effect. They require more heat to become separated, and hence the CPT increases. Some of the water molecules are not attached to any individual micelle in particular, but to the micelle system, forming buffers between micelles, and thereby decreasing micelle-micelle interaction. More energy is required to remove these 'free floating' water molecules, and hence CPT increases with surfactant concentration.

The cloud-point temperature increases with increase in solute concentration for both Triton X-114 and Tergitol NP-7. The increase in cloud-point may be due to the increased hydrophilic character of the surfactant micelle ${ }^{34}$. As the solute concentration increases, it requires more heat for the cloud formation, i.e. for the interaction between solute and surfactant, and to remove water molecules from the external layer of micelle. Therefore, the cloudpoints of Tergitol NP-7 and Triton X-114 increase with the concentration of crystal violet.

\section{Effect of surfactant concentration on CPE}

The surfactant and dye substrate can bind together, and there is an equilibrium relation between them. Surfactant molecules can bind to the dye substrate either monomeric or micellar (by one or more of their molecules) ${ }^{35}$. In addition to the interaction with substrate molecules, surfactants can sometimes form ion pairs with them. Non-ionic surfactants attack cationic crystal violet dye, and cause the formation of dye-surfactant ion pair ${ }^{36}$.

The mechanism between crystal violet dye substrate and non-ionic surfactants may be characterised by the Piszkiewicz model with some modifications $^{35}$. According to this model, the dye substrate molecule associates with ' $n$ ' number molecules of surfactant to form a micelle, where ' $n$ ' is called the cooperativity index and is a measure of the association of additional surfactant molecules to an aggregate in the whole surfactant concentration range. If the value of the cooperativity index is greater than unity, the interaction between dye substrate and sur- factant molecule is positive; and if the value is less than unity, the dye substrate-surfactant interaction is negative; and if the value is equal to 1 , the interaction is non-cooperative.

The aqueous solution of non-ionic surfactants containing crystal violet was transformed from single isotropic phase to two isotropic phases when the temperature of the solution exceeded the CPT. The dilute phase and the coacervate phase were then analyzed. The effect of surfactant and solute concentrations on design parameters were determined in the present work.

\section{Phase volume ratio}

The phase volume ratio, $R_{V}$, is the ratio of the volume of the surfactant-rich phase $(V)$ to that of the volume of the aqueous phase $\left(V_{w}^{s}\right)$. Figure 6 shows the effect of Triton X-114 and Tergitol NP-7 on phase volume ratio at a temperature of $313 \mathrm{~K}$, and a dye concentration of $50 \mathrm{mg} \mathrm{L}^{-1}$. From the figure, it is observed that the phase volume ratio increases with increase in surfactant concentration at a particular operating temperature and dye concentration for both surfactants. The increase in phase volume ratio with surfactant concentration at a constant feed of dye may be due to the increased capability of the surfactant to solubilize the dye. At lower concentration, surfactant molecules exist as monomers. In this case, Triton X-114, less than or equal to $0.02 \mathrm{M}$, does not have the ability of phase separation. At higher surfactant concentration, i.e. above $0.02 \mathrm{M}$, there would be more micellar interaction, and hence all the solute molecules present in the mixture settled along with the surfactant in the coacervate phase. As the concentration of surfactant increases, the volume of coacervate phase also increases, thus decreasing the volume of dilute phase, which results in increased phase volume ratio, $R_{v}$.

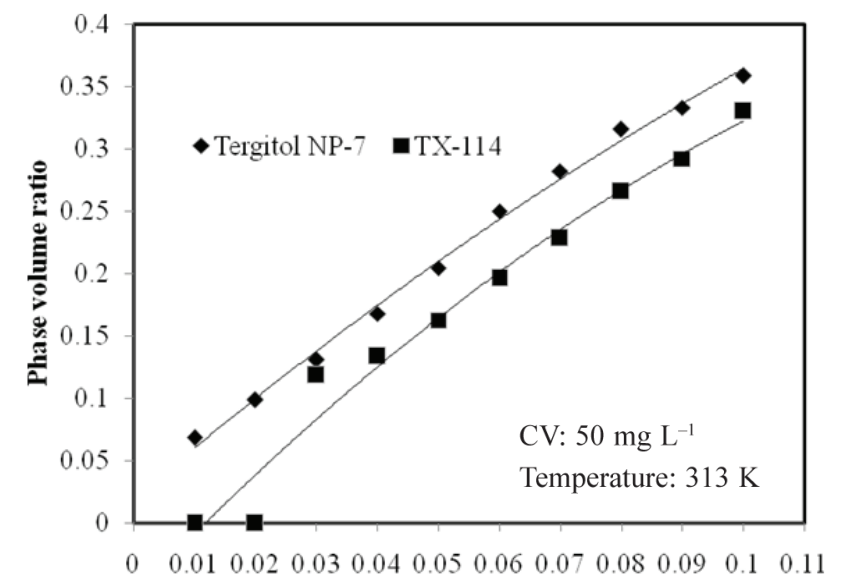

Surfactant concentration (M)

Fig. 6 - Effect of Tergitol NP-7 and Triton X-114 on phase volume 
Figure 6 also shows more phase volume for Tergitol NP-7, in comparison to the Triton X-114. The higher the phase volume ratio is, the greater is the separation achieved for a constant feed concentration. The increase in phase volume is due to the interaction of more surfactant micelle with the dye in the coacervate phase after phase separation. As the concentration of surfactant increases, the number of micelles will increase, leading to greater solubilization.

\section{Preconcentration factor}

The preconcentration factor, $f_{c}$, is the ratio of the volume of bulk solution before phase separation $(V)$ to that of the surfactant-rich phase after phase separation $(V)$. The preconcentration factor is an indication of the ratio of solute concentration in the feed to that in the surfactant-rich phase. For higher value of preconcentration factor, the separation of solute will be lower, and vice versa. From Figure 7, it is clear that the preconcentration factor decreases with an increase in concentration of Triton X-114 and Tergitol NP-7. Tergitol NP-7 has lower volumes of preconcentration in comparison to Triton X-114. Because of the high solubility of solute, it is observed that the preconcentration factor decreases with an increase in surfactant concentration at constant operating temperature and dye concentration ${ }^{36,37}$.

\section{Distribution coefficient}

The distribution coefficient or equilibrium partition coefficient, $K_{d}$ or $K_{p}$, is the ratio of the concentration of solute in the surfactant-rich phase $\left(C_{s}\right)$ to the concentration of solute in the dilute phase $\left(C_{w}\right)$. It is the measure of the difference in solubility of a component in two immiscible phases at equilibrium. If the distribution coefficient is higher, then phase separation will be very easy. The distribution

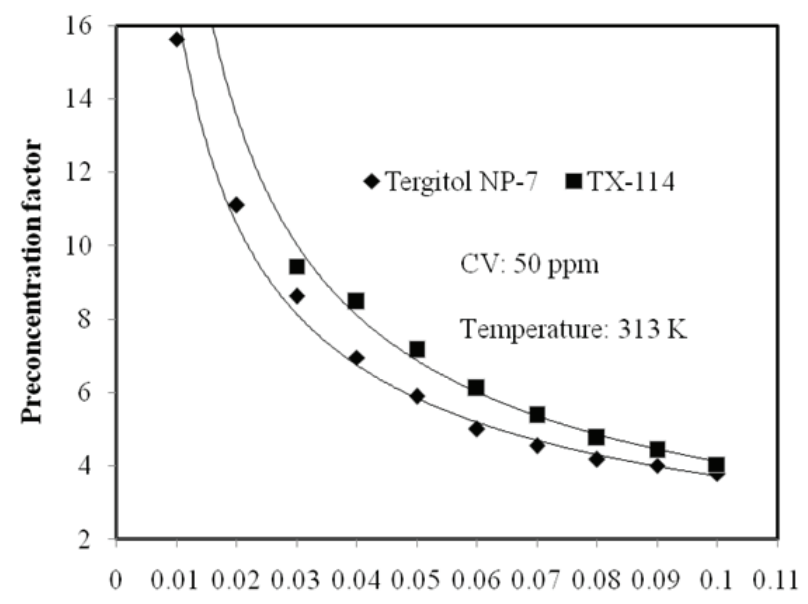

Surfactant concentration $(M)$

Fig. 7 - Effect of Tergitol NP-7 and Triton X-114 on preconcentration factor of solutes depends on the specific solute-solvent interaction. If the interaction is greater, the distribution coefficient will be higher.

From Figure 8, the distribution coefficient increases with the concentration of Tergitol NP-7 and Triton X-114 at constant solute concentration and operating temperature. As the surfactant concentration increases, the system can extract more solute to the surfactant-rich phase, and thereby increase the concentration of solute in coacervate phase for a constant feed dye concentration. The increased solute concentration in coacervate phase leads to higher distribution coefficient at higher Tergitol NP-7 and Triton X-114 concentrations. The results show that Tergitol NP-7 gives a better distribution coefficient than Triton X-114 for the extraction of crystal violet.

\section{Extraction efficiency}

For cloud-point extraction, the efficiency of dye extraction is defined as the ratio of the amount of dye in coacervate phase to that in feed. In other words, the recovery efficiency of solute, $\eta$, can be characterized as the percentage of solute extracted from the bulk solution into the surfactant-rich phase.

$$
\eta \%=\frac{C_{o} V_{t}-C_{w}\left(V_{t}-V_{s}\right)}{C_{o} \cdot V_{t}} \cdot 100
$$

where, $C_{0}$ is the initial concentration of solute in the micellar solution, $C_{W}$ is the concentration of solute in dilute phase, $V_{t}$ is the total feed volume, and $V_{s}$ is the volume of surfactant-rich phase.

The extraction efficiency of dye increases with surfactant concentration at constant solute concentration. As the concentration of surfactant increases, the number of micelles for the extraction process will also be higher, which results in better phase separation, and thus increase in efficiency. With up

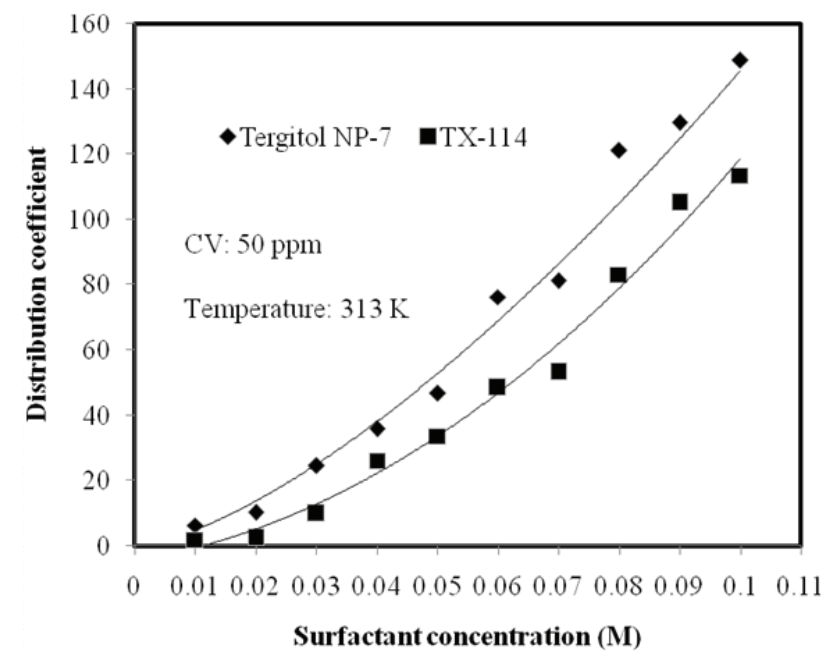

Fig. 8 - Effect of Tergitol NP-7 and Triton X-114 on distribution coefficient 


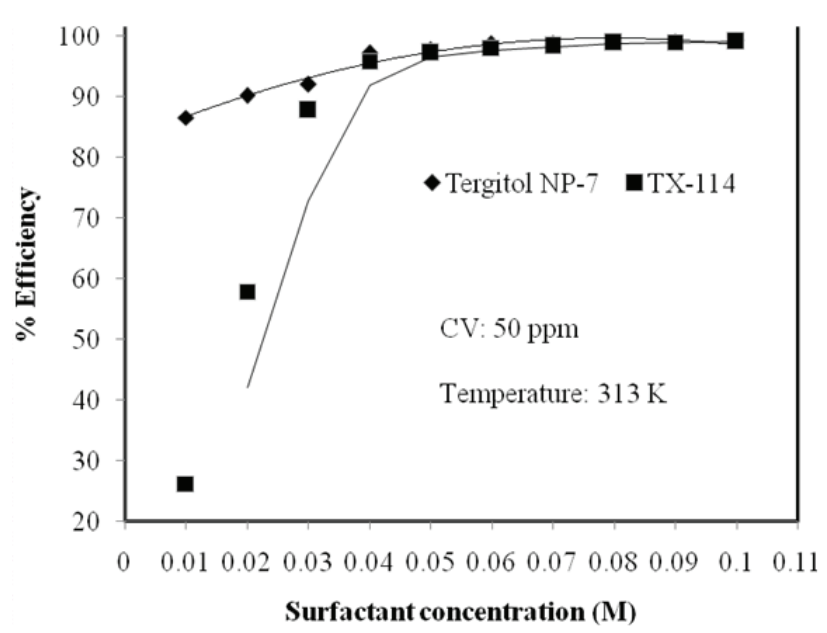

Fig. 9 - Effect of Tergitol NP-7 and Triton X-114 on extraction efficiency

to $0.04 \mathrm{M}$ concentration of Triton $\mathrm{X}-114$, the increase in efficiency is rapid (i.e. 26.18 to $87.85 \%$ ), and gradual after that (i.e. 95 to $99 \%$ ) for a particular concentration of solute $\left(50 \mathrm{mg} \mathrm{L}^{-1}\right)$. More than $95 \%$ efficiency is obtained at $0.04 \mathrm{M}$ concentration of both surfactants for a dye concentration of 50 $\mathrm{mg} \mathrm{L}^{-1}$ (Figure 9). Even at a concentration of 0.01 M, Tergitol NP-7 could extract more than $85 \%$ of the dye molecules from the solution, which suggests that Tergitol NP-7 is more efficient than Triton X-114 at low concentrations of surfactant. For a same degree of polyoxyethylation, polyoxyethlene nonylphenols (Tergitol NP-7) have lower CMCs than polyoxyethylene octylphenols (Triton X-114) ${ }^{38}$. The difference in alkyl group size leads to such a large difference in CMC and hence supports the fact that Tergitol NP-7 is more effective than Triton $\mathrm{X}-114$.

Table 1 - Variation of phase volume with dye and surfactant concentration at $313 \mathrm{~K}$

\begin{tabular}{c|c|c|c|c}
\hline \multirow{2}{*}{$\begin{array}{c}\text { Surfactant } \\
\begin{array}{c}\text { concentration } \\
(\mathrm{M})\end{array}\end{array}$} & \multicolumn{2}{|c|}{$\begin{array}{c}\text { Phase volume } \\
\text { at } 25 \mathrm{mg} \mathrm{L} \mathrm{m}^{-1} \mathrm{CV}\end{array}$} & \multicolumn{2}{c}{$\begin{array}{c}\text { Phase volume } \\
\text { at } 50 \mathrm{mg} \mathrm{L}^{-1} \mathrm{CV}\end{array}$} \\
\cline { 2 - 5 } & $\begin{array}{c}\text { Tergitol } \\
\text { NP-7 }\end{array}$ & TX-114 & $\begin{array}{c}\text { Tergitol } \\
\text { NP-7 }\end{array}$ & TX-114 \\
\hline 0.01 & 0.040 & 0.000 & 0.068 & - \\
0.02 & 0.048 & 0.046 & 0.099 & 0 \\
0.03 & 0.097 & 0.092 & 0.131 & 0.119 \\
0.04 & 0.121 & 0.139 & 0.168 & 0.153 \\
0.05 & 0.167 & 0.152 & 0.204 & 0.163 \\
0.06 & 0.207 & 0.175 & 0.250 & 0.196 \\
0.07 & 0.232 & 0.225 & 0.282 & 0.229 \\
0.08 & 0.265 & 0.246 & 0.316 & 0.266 \\
0.09 & 0.285 & 0.279 & 0.333 & 0.291 \\
0.10 & 0.322 & 0.288 & 0.359 & 0.329 \\
\hline
\end{tabular}

\section{Effect of dye concentration on CPE}

Initially, at a particular operating temperature and concentration of surfactant, extraction efficiency of dye decreases with concentration of crystal violet. The extraction efficiency decreases with the concentration of crystal violet up to a surfactant concentration of $0.04 \mathrm{M}$ (Table 1). Then the effect of dye concentration on extraction efficiency is negligible because the maximum amount of solute is extracted with that particular surfactant concentration and the efficiency reaches $99 \%$. At lower concentration of surfactants, more dye molecules will be present in the dilute phase with an increase in solute concentration, thus decreasing the efficiency. For Triton X-114 as well as Tergitol NP-7, a surfactant concentration of $0.05 \mathrm{M}$ may be considered as the optimum dose for efficient CPE of crystal violet dye up to $50 \mathrm{mg} \mathrm{L}^{-1}$. The introduction of dye molecules to the aqueous solution of non-ionic surfactant will increase the critical micellar concentration of that particular surfactant. Therefore, with the increase in dye concentration, the number of micelles in the solution will decrease, which results in more of unsolubilized dye molecules in the dilute phase after phase separation. Due to this, the extraction efficiency decreases with an increase in dye concentration for a constant surfactant concentration and operating temperature ${ }^{40}$.

\section{Effect of operating temperature on CPE}

The phase volume ratio decreases with increase in temperature at constant dye concentration (Table 2). As the operating temperature increases, micellar interaction will be greater, which leads to the dehy-

Table 2 - Variation of preconcentration factor with dye and surfactant concentration at $313 \mathrm{~K}$

\begin{tabular}{|c|c|c|c|c|}
\hline \multirow{2}{*}{$\begin{array}{l}\text { Surfactant } \\
\text { concentration } \\
\text { (M) }\end{array}$} & \multicolumn{2}{|c|}{$\begin{array}{l}\text { Preconcentration factor } \\
\text { at } 25 \mathrm{~m} \mathrm{~L} \mathrm{~L}^{-1} \mathrm{CV}\end{array}$} & \multicolumn{2}{|c|}{$\begin{array}{l}\text { Preconcentration factor } \\
\text { at } 50 \mathrm{mg} \mathrm{L}^{-1} \mathrm{CV}\end{array}$} \\
\hline & $\begin{array}{l}\text { Tergitol } \\
\text { NP-7 }\end{array}$ & TX-114 & $\begin{array}{l}\text { Tergitol } \\
\text { NP-7 }\end{array}$ & TX-114 \\
\hline 0.01 & 23.00 & 0.00 & 15.62 & - \\
\hline 0.02 & 20.67 & 26.32 & 11.11 & - \\
\hline 0.03 & 19.05 & 11.90 & 8.62 & 9.43 \\
\hline 0.04 & 18.26 & 9.43 & 6.94 & 8.47 \\
\hline 0.05 & 17.05 & 7.50 & 5.88 & 7.14 \\
\hline 0.06 & 16.14 & 7.00 & 5.00 & 6.09 \\
\hline 0.07 & 15.32 & 6.10 & 4.54 & 5.37 \\
\hline 0.08 & 13.76 & 5.43 & 4.16 & 4.76 \\
\hline 0.09 & 12.51 & 4.80 & 4.00 & 4.42 \\
\hline 0.10 & 10.10 & 4.20 & 3.78 & 4.03 \\
\hline
\end{tabular}




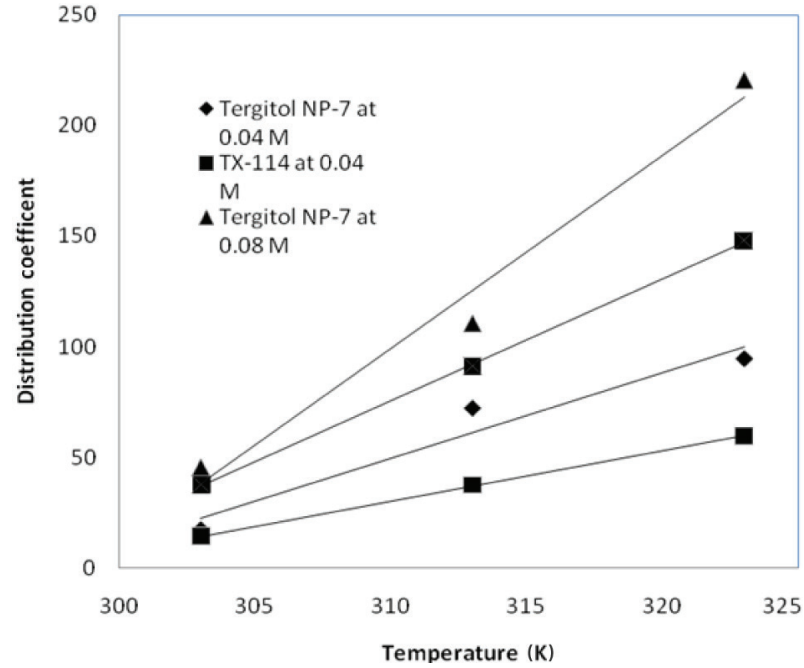

Fig. 10 - Effect of operating temperature and surfactant concentration on distribution coefficent at a dye concentration of $25 \mathrm{mg} \mathrm{L}^{-1}$

dration from external layers of micelles, resulting in a reduction in volume of coacervate phase. Hence, the phase volume ratio decreases with operating temperature. Table 3 and Table 4 suggest that the operating temperature has a great impact on the distribution coefficient as well as the preconcentration factor. The feed volume remains constant at $50 \mathrm{~mL}$. Due to the reduction in volume of surfactant-rich phase, the preconcentration factor increases with operating temperature. Figure 10 shows that the distribution coefficient increases with operating temperature for a particular dye concentration ${ }^{32,39}$. As the temperature increases, the micellar interaction, which was repulsive at lower temperatures, becomes attractive, and hence the micellar aggregation number increases. This leads to increased solubilization

Table 3 -Variation of distribution coefficient with dye and surfactant concentration at $313 \mathrm{~K}$

\begin{tabular}{c|c|c|c|c}
\hline \multirow{2}{*}{$\begin{array}{c}\text { Surfactant } \\
\begin{array}{c}\text { concentration } \\
(\mathrm{M})\end{array}\end{array}$} & \multicolumn{2}{|c|}{$\begin{array}{c}\text { Distribution coefficient } \\
\text { at } 25 \mathrm{mg} \mathrm{L}\end{array}$} & \multicolumn{2}{|c}{$\begin{array}{c}\text { Distribution coefficient } \\
\text { at } 50 \mathrm{mg} \mathrm{L}^{-1} \mathrm{CV}\end{array}$} \\
\cline { 2 - 5 } $\begin{array}{c}\text { Tergitol } \\
\text { NP-7 }\end{array}$ & TX-114 & $\begin{array}{c}\text { Tergitol } \\
\text { NP-7 }\end{array}$ & TX-114 \\
\hline 0.01 & 16.58 & 0.39 & 6.45 & 0.38 \\
0.02 & 28.09 & 0.91 & 10.31 & 0.58 \\
0.03 & 49.01 & 21.73 & 24.66 & 13.41 \\
0.04 & 72.23 & 37.48 & 35.95 & 27.23 \\
0.05 & 80.66 & 55.62 & 46.75 & 42.62 \\
0.06 & 91.61 & 80.91 & 76.35 & 60.47 \\
0.07 & 100.03 & 118.78 & 81.22 & 73.22 \\
0.08 & 110.63 & 141.21 & 121.14 & 103.96 \\
0.09 & 124.95 & 163.28 & 129.64 & 123.65 \\
0.10 & 185.64 & 179.87 & 148.77 & 133.58 \\
\hline
\end{tabular}

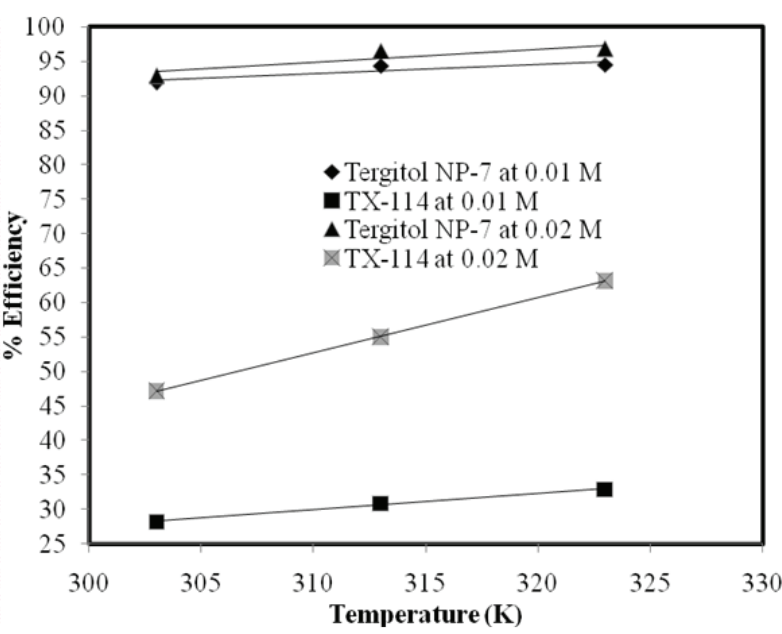

Fig. 11 - Effect of operating temperature and surfactant concentration on extraction efficiency at a dye concentration of $25 \mathrm{mg} \mathrm{L^{-1 }}$

of dye in the surfactant-rich phase, and thus increased solute concentration in coacervate phase, which leads to a higher distribution coefficient.

As shown in Figure 11, the efficiency of extraction increases with operating temperature for Triton X-114 as well as Tergitol NP-7. However, the impact of operating temperature is greater on Triton X-114 than on Tergitol NP-7. CMC of non-ionic surfactants decreases with temperature ${ }^{41}$. Because of an equilibrium shift that favors dehydration of ether oxygen, these non-ionic surfactants become hydrophobic at higher operating temperatures $^{42}$. Hence, the efficiency of extraction of crystal violet increases with operating temperature because of the increased solubilization of dye resulting from increased micellar size and aggregation number.

Table 4 -Variation of extraction efficiency with dye and surfactant concentration

\begin{tabular}{c|c|c|c|c}
\hline \multirow{2}{*}{$\begin{array}{c}\text { Surfactant } \\
\text { concentration } \\
(\mathrm{M})\end{array}$} & \multicolumn{2}{|c|}{$\begin{array}{c}\text { \% Efficiency at } \\
25 \mathrm{mg} \mathrm{L} \text { }\end{array}$} & \multicolumn{2}{c}{$\begin{array}{c}\text { \% Efficiency at } \\
50 \mathrm{mg} \mathrm{L} \mathrm{L}^{-1} \mathrm{CV}\end{array}$} \\
\cline { 2 - 5 } & $\begin{array}{c}\text { Tergitol } \\
\text { NP-7 }\end{array}$ & TX-114 & $\begin{array}{c}\text { Tergitol } \\
\text { NP-7 }\end{array}$ & TX-114 \\
\hline 0.01 & 94.31 & 30.90 & 86.53 & 26.18 \\
0.02 & 96.56 & 54.96 & 91.18 & 57.90 \\
0.03 & 98.02 & 95.68 & 96.08 & 87.85 \\
0.04 & 98.64 & 97.55 & 97.24 & 95.83 \\
0.05 & 98.77 & 98.67 & 97.88 & 97.30 \\
0.06 & 98.90 & 99.01 & 98.67 & 98.08 \\
0.07 & 99.01 & 99.14 & 98.75 & 98.41 \\
0.08 & 99.11 & 99.32 & 99.14 & 98.88 \\
0.09 & 99.22 & 99.40 & 99.21 & 99.05 \\
0.10 & 99.47 & 99.60 & 99.32 & 99.12 \\
\hline
\end{tabular}


Table 5 -Variation of phase volume with temperature and surfactant concentration at dye concentration of $25 \mathrm{mg} \mathrm{L}^{-1}$

\begin{tabular}{c|c|c|c|c}
\hline \multirow{2}{*}{$\begin{array}{c}\text { Surfactant } \\
\text { concentration } \\
(\mathrm{M})\end{array}$} & \multicolumn{2}{|c|}{$\begin{array}{c}\text { Phase volume } \\
\text { at } 313 \mathrm{~K}\end{array}$} & \multicolumn{2}{c}{$\begin{array}{c}\text { Phase volume } \\
\text { at } 323 \mathrm{~K}\end{array}$} \\
\cline { 2 - 5 } & $\begin{array}{c}\text { Tergitol } \\
\text { NP-7 }\end{array}$ & TX-114 & $\begin{array}{c}\text { Tergitol } \\
\text { NP-7 }\end{array}$ & TX-114 \\
\hline 0.01 & 0.04 & 0.00 & 0.03 & 0.00 \\
0.02 & 0.04 & 0.04 & 0.04 & 0.39 \\
0.03 & 0.09 & 0.09 & 0.07 & 0.09 \\
0.04 & 0.12 & 0.13 & 0.09 & 0.12 \\
0.05 & 0.16 & 0.15 & 0.13 & 0.13 \\
0.06 & 0.20 & 0.17 & 0.17 & 0.15 \\
0.07 & 0.23 & 0.22 & 0.20 & 0.19 \\
0.08 & 0.26 & 0.24 & 0.23 & 0.21 \\
0.09 & 0.28 & 0.27 & 0.26 & 0.23 \\
0.10 & 0.32 & 0.28 & 0.27 & 0.25 \\
\hline
\end{tabular}

Table 6 - Variation of preconcentration factor with temperature and surfactant concentration at dye concentration of $25 \mathrm{mg} \mathrm{L^{-1 }}$

\begin{tabular}{c|c|c|c|c}
\hline \multirow{2}{*}{$\begin{array}{c}\text { Surfactant } \\
\begin{array}{c}\text { concentration } \\
(\mathrm{M})\end{array}\end{array}$} & $\begin{array}{c}\text { Preconcentration factor } \\
\text { at } 313 \mathrm{~K}\end{array}$ & $\begin{array}{c}\text { Preconcentration factor } \\
\text { at } 323 \mathrm{~K}\end{array}$ \\
\cline { 2 - 5 } & $\begin{array}{c}\text { Tergitol } \\
\text { NP-7 }\end{array}$ & TX-114 & $\begin{array}{c}\text { Tergitol } \\
\text { NP-7 }\end{array}$ & TX-114 \\
\hline 0.01 & 23.00 & 0.00 & 27.73 & 0.00 \\
0.02 & 20.67 & 26.32 & 25.67 & 27.78 \\
0.03 & 19.05 & 11.90 & 20.87 & 13.77 \\
0.04 & 18.26 & 9.43 & 19.20 & 11.01 \\
0.05 & 17.05 & 7.50 & 18.02 & 8.33 \\
0.06 & 16.14 & 7.00 & 17.44 & 7.35 \\
0.07 & 15.32 & 6.10 & 16.25 & 7.12 \\
0.08 & 13.76 & 5.43 & 14.90 & 6.00 \\
0.09 & 12.51 & 4.80 & 13.67 & 5.57 \\
0.10 & 10.10 & 4.20 & 12.35 & 4.81 \\
\hline
\end{tabular}

\section{Conclusion}

Cloud-point extraction was successfully implemented to remove crystal violet from synthetic dye solution using Triton X-114 and Tergitol NP-7 as non-ionic surfactants. The clouding patterns of Tergitol NP-7 and Triton X-114 with respect to surfactant and solute concentrations were analyzed. The effect of dye concentration, surfactant concentration, and operating temperature on various design parameters of CPE was evaluated. The phase volume ratio was found to increase with surfactant concentration, whereas it decreased with operating temperature. It was observed that the phase volume ratio was inversely proportional to the preconcentration factor, with respect to surfactant concentration and operating temperature. The concentration of solute present in the surfactant-rich phase increased with operating temperature and surfactant concentration, which resulted in a higher distribution coefficient as well as extraction efficiency. From the experimental results, it was observed that, for dye concentrations of $25 \mathrm{mg} \mathrm{L}^{-1}$ and $50 \mathrm{mg} \mathrm{L}^{-1}$, quantitative recoveries $(>97 \%)$ were obtained in a single extraction. It was concluded that the removal of dye from aqueous solution was more effective by cloud-point extraction with non-ionic surfactants. From the performance of Tergitol NP-7 and Triton $\mathrm{X}-114$, it was confirmed that Tergitol NP-7 could extract more crystal violet even at very low surfactant concentration than Triton X-114. The cloudpoint extraction procedure described above is safe, rapid, effective, and inexpensive. Moreover, the cloud-point extraction strategy can easily be adopted for large-scale samples.

\section{ACKNOWLEDGEMENT}

This work is partially supported by the Tamil Nadu State Council for Science and Technology (TNSCST/S\&T project/VR/ES/2009-2010). The authors wish to thank Tamil Nadu State Council Science and Technology for their financial support.

\footnotetext{
Nomenclature

CPE - cloud-point extraction

CPT - cloud-point temperature (K)

TX-114 - Triton X-114

$R_{v} \quad-$ phase volume ratio (-)

$V_{s} \quad-$ volume of surfactant-rich phase (L)

$V_{w} \quad-$ volume of dilute phase (L)

$f_{c} \quad-$ preconcentration factor $(-)$

$V_{t} \quad-$ volume of bulk solution before phase separation (L)

$K_{\mathrm{d}} \quad-$ distribution coefficient (-)

$C_{s} \quad-$ concentration of solute in surfactant-rich phase $\left(\mathrm{mg} \mathrm{L}^{-1}\right)$

$C_{w} \quad-$ concentration of solute in dilute phase $\left(\mathrm{mg} \mathrm{L}^{-1}\right)$

$C_{0} \quad-$ initial concentration of solute in micellar solution $\left(\mathrm{mg} \mathrm{L}^{-1}\right)$
}

\section{References}

1. Purkait, M. K., Banerjee, S., Mewara, S., DasGupta, S., De, $S$., Cloud point extraction of toxic eosin dye using Triton X-100 as nonionic surfactant, Water Res. 39 (2005) 3885. doi: http://dx.doi.org/10.1016/j.watres.2005.07.034 
2. Haddou, B., Bouberka, Z., Derriche, Z., Separation of Neutral Red and Methylene Blue from Wastewater using Two Aqueous Phase Extraction Methods, Sep. Sci Tech. 42 (2007) 2677.

doi: http://dx.doi.org/10.1080/01496390701514774

3. Singh. K. P., Mohan, D., Sinha, S., Tondon, G. S., Ghosh, $D$., Colour removal from wastewater using low/cost activated carbon derived from agricultural waste material. Ind. Eng. Chem. Res. 42 (2003) 1965 doi: http://dx.doi.org/10.1021/ie020800d

4. Pourreza, N., Elhami, Sh., Removal of malachite green from water samples by cloud point extraction using Triton X-100 as non-ionic surfactant, Env. Chem. Lett. 8 (2010) 53. doi: http://dx.doi.org/10.1007/s10311-008-0190-x

5. Asok Adak, Manas Bandyopadhyay, Anjali Pal, Removal of crystal violet dye from wastewater by surfactant-modified alumina, Separation and Purification Technology 44 (2005) 139.

doi: http://dx.doi.org/10.1016/j.seppur.2005.01.002

6. Abedi, S., Nekouei, F., Removal of Direct Yellow 12 from Water Samples by Cloud Point Extraction Using Triton $\mathrm{X}-100$ as Nonionic Surfactant, E-Journal of Chemistry 8 (2011) 1588. doi: http://www.e-journals.net.8 (4) (2011) 1588

7. Amit Kumar, Gaurav Sharma, Mu Naushad, Pardeep Singh, Susheel Kalia, Polyacrylamide / $\mathrm{Ni}_{02} \mathrm{Zn}_{0.98} \mathrm{O}$ Nanocomposite with High Solar Light Photocatalytic Activity and Efficient Adsorption Capacity for Toxic Dye Removal, Journal of Industrial and Engineering Chemistry Research $\mathbf{5 3}$ (2014) 15549 doi: http://dx.doi.org/10.1021/ie5018173

8. Moonis Ali Khan, Zeid Abdullah Alothman, Mu. Naushad, Mohammad Rizwan Khan, Mohammad Luqman, Desalination and Water Treatment 53 (2015) 515.

9. Purkrait, M. K., Vijay, S. S., Separation of Congo red by surfactant mediated cloud point extraction, Dyes and Pigments 63 (2004) 151. doi: http://dx.doi.org/10.1016/j.dyepig.2004.01.010

10. Gullickson, N. D., Scamehorn, J. F., Harwell, J. H., in: Scamehorn, J. F., Harwell, J. H., (Eds.) Surfactant-Based Separation Processes, Marcel Dekker, New York, 1989, pp 139-152.

11. Quina, F. H., Hinze, W. L., Surfactant-mediated cloud point extractions: An environmentally benign alternative separation approach, Ind. Eng. Chem. Res. 38 (1999) 4150 doi: http://dx.doi.org/10.1021/ie980389n

12. Hinze, W. L., Pramauro, E., A critical review of surfactant-mediated phase separations (cloud-point extraction): Theory and applications, Crit. Rev. Anal. Chem. 24 (1993) 133. doi: http://dx.doi.org/10.1080/10408349308048821

13. Lins de Barros Neto, E., Canselier, J. P., Gourdon, C., Solvent Extraction for the $21^{\text {st }}$ Century, SCI, London, UK, 2001, pp 171-176.

14. Akita, S., Takeuchi H., Cloud-point extraction of organic compounds from aqueous solutions with nonionic surfactant, Sep. Sci. Tech. 30 (1995) 833 doi: http://dx.doi.org/10.1080/01496399508013895

15. Akita, S., Takeuchi, H., Equilibrium distribution of aromatic compounds between aqueous solution and coacervate of nonionic surfactants, Sep. Sci. Tech. 31 (1996) 401 doi: http://dx.doi.org/10.1080/01496399608000703

16. Frankewish, R. P., Hinze, W. L., Evaluation and optimization of the factors affecting nonionic surfactant-mediated phase separations, Anal. Chem. 66 (1994) 944 doi: http://www.e-journals.net.8
17. Donbrow, M., Azaz E., Solubilization of phenolic compounds in non-ionic surface-active agents, J. Colloid Interface Sci. 57 (1976) 20. doi: http://dx.doi.org/10.1016/0021-9797(76)90170-3

18. Materna, K., Szymanowski, J., Separation of phenols from aqueous micellar solutions by cloud point extraction, J. Colloid Interface Sci. 255 (2002) 195. doi: http://dx.doi.org/10.1006/jcis.2002.8613

19. Materna, K., Milosz, I., Miesiac, I., Cote, G., Szymanowski, $J$., Removal of phenols from aqueous streams by the cloud point extraction technique with oxyethylatedmethyl dodecanoates as surfactants, Environ. Sci. Tech. 35 (2001) 2341 . doi: http://dx.doi.org/10.1021/es000025y

20. Trakultamupatam, P., Scamehorn, J. F., Osuwan, S., Removal of volatile aromatic contaminants from wastewater by cloud point extraction, Sep. Sci. Tech. 37 (2002) 1291. doi: http://dx.doi.org/10.1081/SS-120002612

21. Kimchuwanit, W., Scamehorn, J. F., Osuwan, S., Harwell, J. $H$., Haller, K. J., Use of a micellar-rich coacervate phase to extract trichloroethylene from water, Sep. Sci. Tech. 35 (2000) 1991 doi: http://dx.doi.org/10.1081/SS-100102085

22. Dongshunbai, Jingliangli, Chen, S. B., Chen B. H., A Novel Cloud-Point Extraction Process for Preconcentrating Selected Polycyclic Aromatic Hydrocarbons in Aqueous Solution, Environ. Sci. Tech. 35 (2001) 3936. doi: http://dx.doi.org/10.1021/es0108335

23. Purkait, M. K., DasGupta, S., De. S., Determination of design parameters for the cloud point extraction of congo red and eosin dyes using TX-100. Sep. Pur. Tech. 51 (2006) 137. doi: http://dx.doi.org/10.1016/j.seppur.2005.12.027

24. Nilsson, P. G., Wennerstrom, H., Lindman, B., Structure of micellar solutions of nonionic surfactants. Nuclear magnetic resonance self-diffusion and proton relaxation studies of poly (ethylene oxide) alkyl ethers, J. Phys. Chem. 87 (1983) 1377. doi: http://dx.doi.org/10.1021/j100231a021

25. DeGiorgio, V., Piazza, R., Corti, M., Minero, C., Critical properties of nonionic micellar solutions, J. Chem. Phys. 82 (1984) 1025

doi: http://dx.doi.org/10.1063/1.448570

26. Lindman, B., Wennerstrom, H., Nonionic Micelles Grow with Increasing Temperature, J. Phys. Chem. 95 (1991) 6053. doi: http://dx.doi.org/10.1021/j100168a063

27. An, L., Deng, J., Zhou, L., Li, H., Chen, F., Wang, H., Liu $Y$., Simultaneous spectrophotometric determination of trace amount of malachite green and crystal violet in water after cloud point extraction using partial least squares regression, J. Hazard Mater. 175 (2010) 883. doi: http://dx.doi.org/10.1016/j.jhazmat.2009.10.092

28. Purkait, M. K., DasGupta, S., De, S., Determination of thermodynamic parameters for the cloud point extraction of different dyes using TX-100 and TX-114, Desalination 244 (2009) 130 . doi: http://dx.doi.org/10.1016/j.desal.2008.04.042

29. Pan, T., Xu, M., Chen, X., Sun, G., Guo, J., Cloud Point Extraction of Four Triphenylmethane Dyes by Triton X-114 as Nonionic Surfactant, Sep. Sci. Tech. 48 (2013) 1040. doi: http://dx.doi.org/10.1080/01496395.2012.726308

30. Katsoyannos, E., Chatzilazarou, A., Gortzi, O., Lalas, S., Konteles, S., Tataridis, P., Application of cloud point extraction using surfactants in the isolation of physical antiox- 
idants (phenols) from olive mill wastewater, PSP Volume 15-No b 2006.

31. Jean-Louis Salager, Surfactants Types and Uses, http:// nanoparticles.org/pdf/Salager-E300A.pdf

32. Jing-Liang, L., Bing-Hung, C., Equilibrium partition of polycyclic aromatic hydrocarbons in a cloud-point extraction process, Journal of Colloid and Interface Science 263 (2003) 625

doi: http://dx.doi.org/10.1016/S0021-9797(03)00403-X

33. Koshy, L., Saiyad, A. H., Rakshit, A. K., The effects of various foreign substances on the cloud point of Triton X 100 and Triton X 114, Coll. Poly. Sci. 274 (1996) 582. doi: http://dx.doi.org/10.1007/BF00655234

34. Weiden, M. H. J., Norton, L. B., The solubilization of hydrocarbons in aqueous solutions of nonionic surfactants, J. Colloid Sci. 8 (1953) 606. doi: http://dx.doi.org/10.1016/0095-8522(53)90049-X

35. Samiey, B., Ashoori, F., Kinetics of Crystal Violet Fading in the Presence of TX-100, DTAB and SDS, Acta Chim. Slov. 223 (2011) 58, 223.

36. Samiey, B., Cheng, C. H., Wu, J., Effects of Surfactants on the Rate of Chemical Reactions, Journal of Chemistry, Volume 2014, Article ID 908476.
37. Bingjia, Y., Li, Y., Qiong, H., Akita, S., Cloud Point Extraction of Polycyclic aromatic hydrocarbons in aqueous solution with Silicon surfactants, Chin. J. Chem. Eng. 15 (2007) 468.

doi: http://dx.doi.org/10.1016/S1004-9541(07)60110-4

38. Nico M. van Os, Nonionic Surfactants: Organic Chemistry, Surfactant Science Series, volume 72 (1998) 66

39. Sicilia, D., Rubio, S., Pérez-Bendito, D., Evaluation of the factors affecting extraction of organic compounds based on the acid-induced phase cloud point approach, Analytica Chimica Acta 460 (2002) 13. doi: http://dx.doi.org/10.1016/S0003-2670(02)00148-4

40. Purkait, M. K., DasGupta, S., Deb S., Performance of TX-100 and TX-114 for the separation of chrysoidine dye using cloud point extraction, J. Hazard Mater. B137 (2006) 827. doi: http://dx.doi.org/10.1016/j.jhazmat.2006.03.003

41. Clint, J. H., Surfactant Aggregation, Blackie, Glasgow, 1992, p. 154. doi: http://dx.doi.org/10.1007/978-94-011-2272-6

42. Hiemenz, P. C., Rajagopalan, R. H., Principles of Colloid and Surface Chemistry, $3^{\text {rd }}$ ed., Marcel Dekker Inc., New York, 1997, pp 37. 